\title{
La noción de síntoma en la intersección entre clínica médica y clínica psicoanalítica
}

\author{
The notion of symptom at the intersection between the \\ psychoanalitical clinic and the medical clinic
}

\author{
Mario Sergio Kelman \\ Consejo de Investigaciones, Facultad de Psicología \\ Universidad Nacional de Rosario, Argentina \\ Dirección postal: 3 de Febrero 1078 - PA - Dto. “2” \\ 2000 Rosario (Provincia de Santa Fe) - República Argentina \\ Ce: mskelman@ciudad.com.ar - mkelman@sinectis.com.ar
}

\begin{abstract}
Resumen. Existe una vasta área de síntomas y fenómenos que se manifiestan en el organismo, que conciernen tanto a la clínica médica como a la clínica psicoanalítica. Ambas abordan lo patológico a través del síntoma, pero recortan distintos reales y proponen incidencias y tratamientos diferenciales del cuerpo y del goce. En consecuencia, resulta necesario abordar un estudio diferencial de la noción de síntoma, organizado en torno al signo-semiológico y en torno a la letra respectivamente. La clínica psicoanalítica no se opone ni excluye a la clínica médica; sino que por el contrario, la continúa. El psicoanálisis restituye la condición de verdad y de goce del síntoma que el discurso de la ciencia elide. Los saberes hacen sistema y los discursos compiten. No hay intersección posible entre medicina y psicoanálisis sino en el espacio de inconsistencia de saber, del límite del saber de uno y otro.
\end{abstract}

Palabras clave: síntoma, medicina, psicoanálisis, verdad, goce.

Abstract. There is a vast area of symptoms and phenomena that appear in the organism, which concern both the medical clinic and the psychoanalytic clinic. Both approach the pathological thing through the symptom, but they cut away different reals and propose incidents and differential treatments of the body and the jouissance. In consequence, it turns out necessary to approach a differential study of the notion of symptom, organized concerning the semiologycal-sign and concerning the letter respectively. The psychoanalytic clinic is neither excluded nor opposed to the medical clinic; on the contrary, it continues it. The psychoanalysis returns the condition of the truth and of jouissance of the symptom that the speech of the science elides. The knowledge do system and the speeches compete. There is no possible intersection between medicine and psychoanalysis except in the fault precisely, and in the space of inconsistency of the knowledge, in the limit between one and the other.

Key Words: symptom, medicine, psychoanalysis, truth, jouissance. 


\section{Introducción}

El presente artículo surge de la práctica sostenida en el Centro Regional de Salud Mental Dr. Agudo Ávila, dedicado a la atención de psicosis y neurosis graves, durante diez años; en el Servicio de Oncología del Hospital Provincial de Rosario, dirigido por el Dr. Miguel Muñoz, durante tres años; en la Unidad de Terapia Radiante "Cumbres" dirigida por el Dr. Ricardo Miecchi, durante siete años; y muy particularmente, en el Seminario de Neurociencia dirigido por el Dr. Jorge Nagel (Diagnóstico por Imágenes) y el Dr. José María Vincenti (Neurología) ${ }^{1}$, en reuniones semanales a lo largo de nueve años. Este último dispositivo consistía en la presentación de pacientes de alta complejidad, con la finalidad de evaluar y establecer un diagnóstico diferencial y sugerir un plan terapéutico, a cargo de un equipo pluridisciplinario y con diversas especialidades médicas.

En dicha experiencia ha sido posible verificar la existencia de una vasta área de síntomas y fenómenos que se manifiestan en el organismo y que conciernen tanto a la clínica médica como a la clínica psicoanalítica. La pregunta surge naturalmente:

¿Cómo especificar condiciones de interlocución en un espacio constituido por la intersección entre ambas clínicas?

Interfase medicina-psicoanálisis. Una relación coadywvante entre saberes intersectados en la biancia de no-saber

Una respuesta a dicha pregunta estaría ejemplificada en la propuesta de Ansermet \& Magistretti, a través del hallazgo de un elemento convergente que materialice una interfase entre medicina y psicoanálisis (Ansermet \& Magistretti, 2004).

Ambos autores recorren críticamente los modelos epistémicos de heterogeneidad e interacción, superposición excluyente y reunión complementaria. Finalmente proponen y optan por la intersección común de uno y otro dominio discursivo a partir de un acontecimiento y de una referencia común.

El acontecimiento apuntado es la formalización del concepto de plasticidad neuronal que reintroduce la singularidad en la clínica médica. Se acepta que el sistema neuronal es susceptible de modificaciones, en cuanto a la reproducción de las neuronas, la reparación a través de zonas y vías supletorias de las que pudieran lesionarse, e incluso la definición de que la

\footnotetext{
${ }^{1}$ Seminario de Neurociencia del Instituto Gamma de Rosario, Provincia de Santa Fe, Argentina.
} 
localización de las zonas corticales varía de individuo en individuo e incluso en un mismo individuo en el curso de su vida.

Se acuña una metáfora real llamada "huella sináptica", que da cuenta de la producción de huellas de estímulos y percepciones directamente inscriptas en el sistema neural. Estas a su vez, darían sustento a una teoría neurológica de la memoria.

Los autores proponen la articulación entre neurociencia y psicoanálisis a partir de la hipótesis de un parentesco entre la huella mnémica freudiana y la huella sináptica neurológica. Proponen de hecho, una actualización sui generis del Proyecto de una Psicología para Neurólogos (Freud, 1895).

La propuesta está fundada en la construcción de un razonamiento por analogía imaginaria que no encuentra un sustento serio, pero proporciona la ilusión de que huella sináptica y huella mnémica fueran dos aspectos de lo mismo, en un orden de co-operación y co-incidencia complementaria. Pero ¿resulta conducente esta lógica epistémica?

Evidentemente, no se trata de pedirle a la medicina que opere según la formulación del psicoanálisis, ni tampoco lo inverso; solicitarle al psicoanálisis que se constituya en un auxiliar de la cura médica.

Hallamos otro ejemplo en los desarrollos del Dr. Eric Kandel sobre las bases biológicas de la memoria, quién también intenta una aproximación al psicoanálisis. La pregunta sería a qué llamar memoria.

Leyendo su texto, Kandel (2007) concibe la memoria como la reiteración de una respuesta, definición que conserva los fundamentos de la antigua teoría del arco reflejo incorporando los recientes desarrollos de la fisiología de la neurona y los conectores sinápticos.

Una y otra vez se intenta sentar las bases de una combinatoria de la asociación de respuestas; en este caso ya no solo en el plano físico sino químico. Luego la inevitable producción de hipótesis suplementarias que añaden complejidad a un fenómeno que de por sí es complejo; mediante la diferente organización modular de la articulación de respuestas.

Cuál es la búsqueda última sino la búsqueda de un elemento, un diferencial que constituya un núcleo mnémico, un soporte de la repetición real tomada como modelo biológico de la memoria. En todo caso, y más allá de la teoría de la memoria, a través de la aprehensión del elemento que soporta lo diferencial, se trata de la interrogación del estatuto del Uno en la generación de la estructura de lo humano.

La ciencia biológica logra despejar un diferencial, pero se trata de un elemento real, químico, cernible y medible; capaz de producir frecuencias orgánicas. Pero es un elemento diferencial real que no soporta el cifrado simbólico que por ejemplo, define un recuerdo, para lo cual es necesario el trazo que soporte el diferencial simbólico.

La hipótesis complementaria de la existencia de la mente no alcanza tampoco para resolverlo, porque solo reduplica en lo imaginario el 
procedimiento biológico, conservando sus técnicas y procedimientos como técnicas imaginarias de resolución en lo real.

En todo caso, el debate científico se traslada a la cuestión que sitúa Lacan luego de su encuentro y diálogo con Chomsky, donde si bien coincide en que el lenguaje es un órgano, polemiza con este sobre si el lenguaje es pasible de pasar íntegramente a la biología, sobre la pretensión de construir una filogénesis del lenguaje en el marco de lo innato y lo adquirido; su carácter específico, y sobre su traducción íntegra en pensamientos con un sesgo conductual.

El debate de Lacan es con las premisas del Programa de Cambridge y no se trata de una discusión menor, dado que se ha conferido a lo mental el estatuto de un órgano.

Por otra parte, si el mismo estudio de Lorenz (Lorenz, 1981 citado en Milner, 2000) sobre el comportamiento, aborda el "a priori" kantiano como un órgano; bien vale repensar la obviedad del estatuto de un órgano; por cuanto este excede a la anatomía biológica y puede constituirse a partir de una función o de una taxonomía.

Lacan, por ejemplo; define a la libido como un órgano, el órganoinstrumento de la pulsión. Retomando así a Freud, abre un campo inédito en donde la prohibición del goce incestuoso es el fundamento de la elección por la toma de la palabra en el campo del lenguaje, en donde una apuesta prefigurada aguarda el advenimiento de un sujeto.

En consecuencia, se advierte con claridad que no se trata de una relación entre medicina y psicoanálisis ni complementaria ni excluyente; sino coadyuvante. Es decir, una relación que acepta la vecindad de saberes y la existencia de aportes parciales que no constituyan oposición ni totalidad, jerarquía ni complementariedad.

Un espacio de interlocución fundado en una vecindad de saberes heterogéneos, en el que los intercambios sean posibles a partir del encuentro del punto de inconsistencia de cada saber, falta inscripta o no-saber que enmarca la producción.

El abordaje de un caso cuyo diagnóstico constituye una incógnita, como se presenta en el dispositivo del Seminario Clínico mencionado, hace visible que todo saber está enmarcado en un no-saber, que todo conjunto epistémico contiene un punto de inconsistencia, una falta de saber que da cuerpo a la causa que sostiene la producción de conocimiento.

En resumen, solo cuando es posible sostenerse en la falla, en la falta de saber; es posible la interrogación y obviamente, la interlocución.

De modo tal que no conviene alinear medicina y psicoanálisis en un orden de dualidades excluyentes. Cada clínica tiene su propio modo de establecer su campo, sus intervenciones, sus efectos y responsabilidades por las consecuencias. 
Se propone una consideración de las clínicas como campos de saberes en una relación de vecindad que pueden operar en forma coadyuvante haciendo lugar a lo heterogéneo; coexistiendo en las diferencias de acuerdo con la incumbencia, decisión y responsabilidad que le compete a cada una.

Formular un dispositivo de trabajo en este marco, ha posibilitado construir una casuística que permite el estudio, discusión e investigación a posteriori del acto clínico, a través de los efectos producidos en el proceso de la cura.

El presente trabajo no pretende un desarrollo exhaustivo, ni abundar en una extensión que agote la variedad de puntos de vista diacrónico y sincrónico de la cuestión; lo que por otra parte, resultaría inabordable. "No hay universo de saber" es un aforismo de Jacques Lacan que expresa que no hay un saber que constituya un todo. Un saber total solo es posible formularlo en la huella de la utopía hegeliana, la cual coincide con la muerte como instancia absoluta o el fin del sistema.

\section{La defensa de la clínica: El riesgo de la prevalencia de la técnica desprendida de la clínica conduce a la objetalización de lo humano}

La perspectiva de este escrito se apoya en el discurso del psicoanálisis y en la orientación que le dieran Freud y Lacan, con el objeto de ceñir un tema tan vasto, a partir de un detalle, de una particularidad. En este caso, la particularidad está dada por el estatuto diferencial del síntoma en la clínica médica y psicoanalítica, del cual deviene el subsiguiente orden de determinación diferencial en ambas praxis.

Tampoco se trata de un desarrollo ecléctico, que deje el problema en un estado de indefinición, disuelto en una variedad equivalente y sin consecuencias.

Todo escrito formula un problema, y su conclusión implica necesariamente una toma de posición definida, abierto al posterior debate e intercambio en la comunidad de pares, en el que sí se aloja la diversidad de posiciones.

El campo de la primera psiquiatría, con una matriz inequívocamente clínica, se reformula a partir de tres situaciones de vastas consecuencias:

1- El surgimiento y la hegemonía de la clínica del psicofármaco, cuya incidencia actual alimenta la prevalencia del interés terapéutico sobre el interés clínico.

2- La propuesta básica que referencia el síntoma como una señal de alteración patológica de una función normal, puesta en relación causal con una zona del cerebro. El órgano cerebral es llevado al lugar de la causa de lo humano. 
3- El desarrollo de una forma actualizada de la neurología conocida como neurociencia, que guarda una importante afinidad epistémica y sistemática con la clínica del fármaco; capaz de incidir a escala molecular, a partir del descubrimiento de los neurotransmisores. La unión entre la psicología cognitiva y el enfoque de la neurología centrada en los casos individuales sentó las bases de la neurociencia o neuropsicología cognitiva.

Una larga tradición inspirada en la zaga que inaugura Franz Gall en el siglo XVIII intenta demostrar la localización cortical de cada función humana, a través del estudio diferencial de casos con lesiones cerebrales. En nuestra época se actualiza y se respalda dicha hipótesis con el uso de la tecnología: Resonancias Magnéticas Nucleares Funcionales, espectogramas y tractografías.

Entre los primeros postulados de Gall y los más recientes desarrollos de la neurociencia interpolamos la secuencia histórica de un conjunto de formalizaciones científicas. Accedemos así, no solo a la evolución de la indagación médica sobre la anatomía y la funcionalidad del cerebro, sino al proceso epistémico de producción de saber en el campo de la ciencia.

Cada formalización se propone como certeza asentada en la evidencia anatómica, cuyo abordaje técnico produce una imagen tecnológica y una metáfora real del órgano que vela la dimensión simbólica de la elaboración científica.

En la secuencia histórica referida se trata de la elaboración de ficciones simbólicas para dar cuenta de los fenómenos y síntomas relevados en la práctica clínica; intentos de cernir lo real propio del campo. Ficciones que siempre semi-dicen una verdad parcial.

La evidencia de la imagen que figura la lesión cerebral aplana y vela el campo clínico. Se extiende la certeza del determinismo de la imagen y del órgano a las siguientes premisas, que por un efecto de arrastre, se dan por igualmente probadas:

- Atribución de la determinación cortical de una función que se ha extendido de lo orgánico a lo subjetivo.

- Deducción de la existencia de una unidad funcional y sintética del cerebro obtenida mediante la duplicación imaginaria del órgano y la producción de un nuevo órgano imaginario asociado, llamado mente; lo cual abre un nuevo campo que da sustento a la ciencia cognitiva. No obstante, la propuesta terapéutica es la misma, eliminar el síntoma del sujeto a través de la incidencia en el órgano biológico del cerebro o del órgano virtual de la mente.

Mediante la tecnología es posible obtener un registro del órgano cada vez más sofisticado. Si bien esta aporta nuevos elementos, también acentúa la paradoja que tiene lugar; por cuanto más se extrema el examen, más aún se evidencia lo que cierne y lo que escapa al registro: lo real del órgano. 
El cognitivismo y el supuesto de la mente es convocado por la biología como un saber complementario para dar cuenta de lo que escapa al registro biológico primario.

La profusión de la imagen y la evidencia positiva de que una lesión cerebral afecta una función, parece una prueba suficiente para otorgar certeza a la presunción de que la función está determinada por el órgano cerebral.

Nos permitimos la objeción de interrogar que si bien los estudios muestran que una lesión de una zona cortical afecta una función ¿ello demuestra acabadamente lo inverso, que el órgano no lesionado determina y produce la función?

De allí la subsistencia de la interrogación clínica, compartida por los propios neurólogos.

El problema fundamental es que no existe una manera sencilla de relacionar las funciones de un trozo de tejido cerebral destruido y las discapacidades que parecen afectar a un paciente como consecuencia de la lesión. Según la idea inicial, simplemente cualquier cosa que un paciente no pudiera hacer estaba normalmente controlada por el área cerebral lesionada. Si una persona tenía una lesión y por ejemplo, no podía ver, se decía que el área dañada controlaba la visión. Si esa persona tenía la lesión en otro lugar y no entendía el lenguaje hablado, se decía que el área implicada era responsable de la comprensión del habla. p. 32).

Esta óptica ha resultado demasiado simplista (Springe \& Deutsch. 2001,

Concluyendo, una expresión más ajustada propondría que el viviente es soporte del sujeto, de modo tal que el órgano biológico es soporte de la función, pero no su causa u origen.

Al párrafo anterior se añaden los recientes descubrimientos sobre la plasticidad neuronal que definitivamente objetan el paradigma de una localización cortical intrínseca de las funciones; abriendo un nuevo campo de interrogaciones y enigmas, que plantea la singularidad y el momento de cada caso, en una configuración de estructura dinámica y variable.

Por supuesto, no se trata de oponerse al empleo de psicofármacos ni al empleo de la tecnología en el campo de la medicina; pero sí de interrogar el marco ético de su uso, debiendo subordinarse a la prevalencia de la posición clínica.

La operación que reduce la subjetividad al órgano cerebral y la incidencia de la tecnología conducen a la objetalización del sujeto bajo el auspicio del discurso científico, con la consiguiente pérdida de la clínica y la exclusión del sujeto del síntoma, del sujeto del sufrimiento.

En la perspectiva clínica del psicoanálisis, claramente la función del sujeto está tomada y profundamente modificada en su estatuto biológico por la toma del viviente efectuada por el lenguaje. 
Dicha modificación de la función del viviente se aprehende en una doble vertiente.

Por una parte, la condición erógena o libidinal de la función y por otra parte, su dimensión de verdad ineludible para el ser hablante, a partir de su relación con el lenguaje.

El hallazgo de Freud (1898) cobra un alcance restitutivo dado que erogeneidad y verdad son vertientes sistemática y radicalmente rechazadas en el abordaje del cuerpo del humano y del síntoma, efectuado por el discurso de la ciencia: por ejemplo, no hay cuerpo de la biología que soporte y de cuenta de las marcas de la prohibición del incesto.

El discurso científico produce un abordaje del cuerpo humano posible solo a partir de la operación cartesiana que enuncia el "pienso, luego soy", dando lugar a la apertura del campo del saber y del sujeto de la ciencia que le es correlativo.

El cogito enmarca el abordaje del cuerpo por parte del discurso de la medicina que recoge la pregunta por el sufrimiento humano e inaugura la tradición clínica.

En términos cartesianos el cuerpo se define como pura sustancia extensa y opuesta a la sustancia pensante, es decir, el cuerpo extenso opuesto al logos.

En una siguiente operación, el cuerpo de la ciencia se constituye vaciando la sustancia extensa de toda condición erógena o libidinal.

En resumen, se trata del cuerpo reducido a su extensión mecánica y despojada de su condición de goce, sobre la cuál es posible operar en su conjunto o descomponiéndola en partes.

Por otra parte, la ciencia apoya su basculación en el campo de un saber siempre elevado a la condición de principio universal, que no quiere saber nada de la dimensión de la verdad y mucho menos de una verdad particular del ser hablante, de cada uno.

El despojo y el desconocimiento no constituyen un hecho fortuito sino sistemático. Por razones de estructura, el discurso de la ciencia se constituye a partir de la forclusión del sujeto singular y de su condición particular de goce.

"Forclusión" es una noción que Lacan (1956) toma de Freud y le da un alcance fundamental en la clínica de las psicosis. Forclusión es un rechazo radical del que no queda huella.

La forclusión es homóloga al "no ha lugar" propio del discurso jurídico. No hay lugar para la inscripción ni su huella, a diferencia de la represión que constituye un modo de rechazo de lo representable, de lo cual queda la huella que se torna sensible en la experiencia analítica, con el reconocimiento de lo reprimido en su retorno. 
La clínica psicoanalítica opera en el campo de lo forcluido por el discurso de la ciencia, incluyendo lo excluido por la ciencia del sufrimiento humano, haciendo lugar a lo que permanecía sin lugar y fuera de discurso.

\section{Estatuto diferencial del síntoma}

Cada clínica se define a través de la estructura del sujeto y la noción de síntoma que concibe y le es propia.

No solo se trata de una definición inherente a su naturaleza, sino que también traza las condiciones de la intervención del clínico y la estrategia de una cura. La noción de síntoma constituye un soporte determinante que establece la clínica diferencial.

La noción de síntoma en la clínica médica se soporta en la estructura del signo. El síntoma médico es la señal de una patología referenciada en el organismo.

En consecuencia, el síntoma médico consta de dos caras: la señal sintomática y su significación en el orden de lo patológico, propia y diferencial, situado a nivel del organismo de la biología.

De este modo, el signo semiológico organiza fuertemente el dominio de sentido del discurso médico. Pero ocurre que de pronto el clínico se encuentra con síntomas que no encuentran causa orgánica, abriendo un campo que objeta la razón nosológica.

Históricamente, la psiquiatría se hizo cargo del campo de la sin-razón, del residuo del sin-sentido que queda por fuera del dominio discursivo de la medicina propiamente dicha. Por lo cual se consideraba que quién padecía un síntoma que no tenía una referencia orgánica, se trataba más bien de un impostor o de un fingimiento propio de un enfermo inauténtico.

Curiosamente la psiquiatría se instituye en el reverso de la locura por quedar ambos en un lugar de la excepción. Excepción al campo de los bienpensantes y cartesianos existentes.

La locura como lugar de la sin-razón instituye el menos-uno del sujeto cartesiano, excepción excluida que a su vez sostiene y coherentiza el discurso de la razón.

Del mismo modo, los síntomas que no tienen su referencia causal en el organismo se exceptúan del conjunto ordenado por el algoritmo semiológico de la medicina general: signo/significado.

Así, la psiquiatría, especialidad surgida tardíamente, se hace cargo del sin-sentido y de hecho no solo que coherentiza sino que comanda retroactivamente la construcción epistémica del campo de sentido propio de la medicina general.

La psiquiatría ha sido históricamente caracterizada como el espacio de deshechos de síntomas que no encuentran una significación orgánica y la 
neurociencia se convoca en la insistencia de suturar la falla del sin-sentido del síntoma que se repite incoerciblemente, aportando una referencia orgánica más sutil.

Reducido y objetivado el sufrimiento subjetivo a una nueva clasificación nosográfica vertida en un conjunto de imágenes cerebrales correlativas a cada patología, comparada con estándares preestablecidos, se configuran protocolos que ordenan la medicación en consecuencia. El ideal científicotecnológico desprendido de la clínica, parece conducir a un refinamiento de la técnica aplicada a un órgano aprehendido en su transparencia, ajustado, calibrado, medicado y reducido a su silencio.

La posición médica imbuida de la tradición hipocrática se pierde en cuanto prevalezca la tendencia terapéutica sobre la clínica. El riesgo se presenta en lo inmediato a través de las consecuencias para la clínica y los pacientes, tomados como objetos de protocolos de una intervención técnica. En forma mediata, el riesgo concierne a la segura producción de crisis y síntomas mayores, ya que lo desconocido y rechazado en el abordaje clínico, retorna seguramente de la peor manera.

Lo rechazado es el orden de verdad singular del ser hablante y de su condición patológica de goce, que la vía del síntoma revela.

El cognitivismo o la clínica del fármaco, cuando establecen un síntoma objetivado desprendido del contexto de la palabra del sujeto, sobre el que se aplica una terapéutica sustentado en la técnica -no solo el fármaco, sino también la sugestión- asume un ejercicio de autoridad que pone las decisiones y la responsabilidad exclusiva del lado del terapeuta, con los riesgos y consecuencias que ello implica.

En la clínica psicoanalítica, el síntoma adquiere una dimensión de verdad que proporciona una perspectiva totalmente diferente en relación con la responsabilidad subjetiva y al contexto de una cura.

La experiencia psicoanalítica implica un poner al trabajo al sujeto acerca de aquello que lo trae a la consulta, debiendo implicarse respecto de la verdad subjetiva en juego y asumir una responsabilidad propia sobre su propia patología. Es decir, que el sujeto siempre es responsable de su problemática particular y de su posición de goce en la estructura, lo que le permitirá situarse de otro modo ante lo que es fuente de su padecimiento y clave de su cura.

De modo consecuente con la lógica explicitada, la potencialidad de la clínica psicoanalítica se sustenta en la noción de síntoma que le es propia, en tanto esta articula el síntoma con el goce y con la verdad a través de la letra, lo cual justifica que en este texto se proponga la noción de síntoma-letra. Un síntoma que vale en tanto escritura de una verdad del sujeto no accesible directamente sino a través del discurso.

El síntoma es aparato que permite la regulación del goce pulsional. 
Por lo anterior, aprehendemos una diferencia fundamental entre la concepción del síntoma en medicina y en psicoanálisis.

En la clínica médica, el síntoma es señal de lo patológico y la cura esperada es su eliminación, incidiendo en el proceso patológico que alteraría la estructura normal.

En la clínica psicoanalítica, una posible definición de lo patológico podría ser la de un goce que lleva a la muerte, con sus diversas variantes, intensidades y modos de retorno. Pero tal goce, es un elemento de estructura, objeto de evacuación correlativa al advenimiento del sujeto.

No por ser rechazado deja de estar presente de algún modo, siendo lo particular de cada sujeto su modo de retorno y de tratamiento.

El síntoma pasa a ser la vía privilegiada, tanto para acceder a su verdad, cuanto para que el sujeto se haga responsable de su propio patológico en el curso de su cura.

Que existan diferentes definiciones del síntoma no significa que deba tomarse una como cierta y descartar las otras. Se trata de tomar cada definición en su contexto y leer el sesgo y abordaje diferente que cada definición revela.

Coexistencia de la clínica médica y la clínica psicoanalitica. Ambas recortan diferentes reales del cuerpo e implican diferentes modalidades de tratamiento del goce

Concluyendo, se ha arribado a que la interrogación del estatuto del síntoma alojado en el espacio de intersección de la clínica médica y la clínica psicoanalítica, requiere de la distinción de la noción de síntoma-signo semiológico y síntoma-letra respectivamente.

Ambos recortan distintos reales y el modo de tratamiento del goce del síntoma implica en la clínica médica y en la clínica psicoanalítica, incidencias y alcances diferentes.

Todo intento de interlocución llevado a cabo bajo la rúbrica de la unificación y supresión de las diferencias, inevitablemente se dirige en contra del propósito planteado.

Si bien la ciencia rechaza la dimensión de la verdad, ello no impide que el saber de la medicina incida en la relación del goce con el cuerpo, lo cual produce efectos y consecuencias.

Del mismo modo, la interpretación analítica conlleva una tramitación del goce. En consecuencia, se trata de una interlocución posible sobre los diversos modos de tratamiento de goce que conlleva la clínica médica y la clínica psicoanalítica.

La época actual está signada por los influjos de la globalización, los cambios vertiginosos que introduce la tecnología y la incidencia del mercado sobre la sociedad civil; lo cual ha tenido su incidencia sobre la subjetividad contemporánea. 
Se ha planteado una nueva casuística caracterizada por una devaluación simbólica del síntoma en su potencia de metáfora, para recostarse en la vertiente de la acción, con una florida producción de fenómenos en el cuerpo. En su extremo opuesto máximo, situamos el dolor desnudo, sin investidura de ninguna naturaleza.

La conversión ya no se aplica como índice patognomónico de la histeria sino que se desliza del campo del inconsciente articulando una restitución de cuerpo en el fenómeno, donde resuena la palabra con el orden de lenguaje rasgo, letra- que circunscribe el goce.

Se abre una consideración nueva de clínica diferencial a partir de una lógica más próxima los fenómenos "phi subcero" (Lacan, 1957) propios de las psicosis, que corresponde al modo de implicación del cuerpo en el anudamiento de las tres dimensiones real-simbólico-imaginario mediante el síntoma o lo que hace las veces de síntoma.

A continuación se incluyen una serie de viñetas clínicas tomadas del archivo de notas, en las que se plantea un uso del dolor por parte del sujeto que tiene el valor de un síntoma en un sentido amplio tal como lo define Lacan. Luego, las notas de archivo de un caso que interroga el diagnóstico de epilepsia.

- Una paciente acude a consulta con el diagnóstico de fibromialgia.

La fibromialgia es un tipo de dolor neuropático de tipo disfuncional que ha pasado a tener en el discurso médico una figuración alternativa respecto de la histeria; de diagnóstico clínico no aprehensible por pruebas complementarias que correlacionan la neuroquímica con la red neurológica de dolor cerebral asociada a la evidencia detectada por imágenes.

En parte evidencia un dolor incierto que migra por diversas regiones del cuerpo localizándose en las terminales nerviosas pero no se trata de un dolor con valor de síntoma histérico. En el testimonio clínico se formula que el dolor irrumpe a partir de una vacilación en la creencia de la existencia, el dolor restituye cuerpo a la creencia permitiendo al sujeto el pasaje a una existencia, en la medida que lo retoma en el discurso.

- Paciente C. que consulta derivada por un médico que presenta un dolor crónico en la fosa ilíaca derecha.

Ha tenido dos cesáreas y diez operaciones producidas luego de un diagnóstico de endometriosis -expansión del endometrio que produce dolor y sangrado en cada ovulación- pero a la cual la paciente describe como una afección en el endometrio del útero y de los ovarios que le hacen producir falsos óvulos u óvulos fallidos. Las numerosas operaciones remiten a la referencia previa de la disección del Uno que conducen a la afectación de la lógica del sentido. 
En una primera entrevista C. se refiere a su largo historial médico, diciendo al pasar que existe un antecedente de endometriosis de su madre, pero que el dolor de ella cesó cuando la operaron una sola vez y le quitaron ovarios y útero.

Interrogada acerca de su padre, recibe la pregunta con cierto gesto de estupefacción y responde balbuceante, "no, mi padre no."

Se reitera un gesto de interrogación y nuevamente responde. "Mi padre no. Me llenó de hermanos" Nuevamente se sostiene la interrogación, y continúa. "Tuvo hijos por todos lados. Averigüé y de algunos me enteré. Tres aquí, dos en la ciudad de..., otros en.... Y así. Nunca estuvo. Mi padre no......." queda en silencio con la vista extraviada.

En esta instancia se constituye la hipótesis de la correlación, por una parte, de una infinitización del lado del sujeto con sangrado en cada ovulación, produciendo colecciones líquidas o falsos óvulos con irrupción de un dolor constante y permanente y, por otra parte, de una infinitización del lado del padre respecto de la inscripción de la filiación.

Se presume como diagnóstico presuntivo un delirio cenestésico. El dolor hace límite ante la infinitización abismal en que se precipita el sujeto. El dolor anuda, da cuerpo y tiene una estructura similar al delirio aún cuando pueda no llegar a constituir un delirio. El dolor interpreta lo real, el dolor lee lo real donde el sujeto no cuenta con el aparato del síntoma.

En esta perspectiva clínica se suscribe la propuesta clínica de Fouchet (2003) de precisar las diversas modalidades de una clínica del sujeto que reintroduzca la dimensión pulsional, precisando una orientación en el acompañamiento terapéutico que tome en cuenta más allá de los efectos de reparación del organismo, el Otro real que los causa, Otro real entendido como lo que vuelve siempre al mismo lugar.

(Nota: Mucho tiempo después de transcurrida la presentación de este caso, llega la noticia de la internación de la paciente en una clínica psiquiátrica debido a una crisis subjetiva. Irrumpe una construcción francamente delirante, pero en esta ocasión expresada a través de su relato. Lo delirante ha pasado del órgano y de la percepción cenestésica, al plano discursivo).

- Paciente: $\mathrm{M}$

1- Motivo de consulta:

M tiene convulsiones desde los 14 años. Pasa por un momento de estabilidad hasta hace algunos meses en que vuelven a aparecer desvanecimientos, amnesia temporal y estados de ausencia. Hace 6 meses contrae un citomegalovirus y dice sufrir una intoxicación con una sustancia con la que fumigan el campo. Sufre colitis, vómitos, decaimiento, dolores articulares en cabeza, huesos y músculos; anemia y un dolor súbito que concluye en lo que ella llama un grito gutural. 
Tiene una importante creencia espiritualista a la que dedica su actividad y estudio dando seminarios en el país y en el exterior, con una modalidad consecuente con las teorías cibernéticas del funcionamiento del cerebro. Apoyándose en sus creencias elabora un mito de surgimiento de sus padecimientos como un aprendizaje que debe realizar en esta vida para evolucionar.

El padre fallece hace 3 años en forma súbita debido a una afección cardiaca. Es la menor de 4 hermanos con una importante diferencia de edad. Un hermano 17 años mayor, otro hermano 15 años mayor y una hermana 10 años mayor que fallece de mal de Hodzking.

A los 28 años se casa embarazada de su hija -que hoy tiene 6 años-, con un partenaire que se revela luego con un carácter diferente al que había conocido. Agresivo y violento llega a golpearla, por lo cual decide su divorcio. Posteriormente forma una nueva pareja con un hombre separado que tiene un hijo del que dice que se interpone entre ambos, sin que el padre le ponga límites. Dice haber encontrado maldad en el niño, incluso haber sentido una presencia maligna y llegado a ver en él, la cara del demonio. Luego de una serie de avatares, este hombre la abandona, lo cual causa en ella una herida y su ofensa, ratificando su idea que no se puede confiar ni creer en ningún hombre.

2- Del diagnóstico de epilepsia y otras consideraciones.

Si bien desde los 14 años siempre ha estado en tratamiento médico, no ha tenido un diagnóstico probado respecto de sus convulsiones, tanto en el país como en el exterior, donde realiza varias consultas a médicos especialistas.

En los últimos tres meses ha tenido intensas crisis convulsivas con pérdida de la conciencia y caídas súbitas que le ocasionan golpes y cortes en la cara, labios, boca y otras partes del cuerpo.

Dado la intensidad de las crisis ha tenido frecuentes internaciones en las que se apela al uso de variadas medicaciones sin obtener el cese de las crisis.

El EEC muestra un trazado normal, y solo un EEC con hiperventilación muestra un trazado con grandes espigas que permite el diagnóstico médico de epilepsia.

Comentario:

Existe una sola referencia sobre la epilepsia en los textos freudianos, "Dostoievsky y el parricidio". La hipótesis de Freud sobre Dostoievsky es que existía en su configuración subjetiva una tendencia a la destrucción y una tendencia sádica muy importante, que metaboliza dirigiéndola contra su propia persona, de modo tal que retorna bajo la forma de masoquismo, sumisión extrema, culpa y epilepsia. 
Dostoievsky se declara epiléptico y se lo tenía por tal. Freud tiene la hipótesis de que la epilepsia era un síntoma de su neurosis, calificándola de histeroepilepsia o histeria grave.

Freud asimismo menciona en ese año que no le resulta la epilepsia una entidad clínica clara. La describe a partir de los rasgos de ataque convulsivo en apariencia no provocados, con alteración del carácter y progresivo desfallecimiento de las operaciones intelectuales.

Plantea la hipótesis de la reacción epiléptica como una descarga pulsional ligada a la sexualidad, es decir como una tramitación a través del organismo de una masa de excitación psíquica. Reconstruye los nexos entre los accesos convulsivos y la vida de Dostoievsky donde destaca tres vivencias: el asesinato de su padre, el abuso sexual cometido contra una niña inmadura y la compulsión al juego y lo que ella encierra.

El antecedente de la epilepsia de Dostoievsky es el estado de dormir letárgico acompañado de angustia de ser dado por muerto, lo que traduce en sí una intencionalidad de muerte. La principal tesis de Freud es que estos síntomas que traducen un perjuicio de sí mismo, se interpretan en Dostoievsky como una identificación con el padre muerto y simultáneamente como ataques de autocastigo por la tendencia agresiva dirigida contra el padre.

Volviendo al testimonio sobre $\mathrm{M}$, refiriéndose a su próximo Seminario Espiritualista, menciona que ya ha recibido las indicaciones sobre los temas, los textos a leer, la estimación previa de que irá un público considerable así como el diseño de los anuncios e invitaciones. Luego de una intervención interrogativa despliega un desarrollo de tono delirante manifestando que ha recibido estos elementos de un Ángel que le aporta los dictados de Dios. Piensa incluir en su Seminario un discurso sobre los Ángeles, de los cuales ha hecho un catálogo y elegido uno como su Ángel personal. Relata un sueño donde atraviesa un túnel de luz que representa aparentemente su paso a una vida en el más allá donde la recibe un Gran Hombre de barba blanca; Dios, que la invita a sentarse a su lado en una gran mesa, lo cual ella rehúsa con la idea de continuar su vida y proyectos pendientes en la Tierra. Interpreta su enfermedad actual como una muestra del enojo de Dios por su rechazo a participar del Banquete celestial.

Comentario:

En la práctica clínica contemporánea encontramos fenómenos en el cuerpo inéditos, que si bien conservan la forma de la conversión como deriva de energía pulsional por vía del organismo, no responden a la forma convencional del síntoma histérico y se encuentran próximos al modo del uso del cuerpo que se verifica en el síntoma en las psicosis.

La conversión ha dejado de ser un signo excluyente de la histeria. Puede ocurrir un síntoma en el cuerpo que no responde a un cifrado asequible para 
el sujeto y se estructura con una lógica propia del síntoma en las psicosis anudando real, simbólico e imaginario.

3- Un acontecimiento imprevisto.

El último acceso de convulsión se produce cuando viajaba en un auto con su madre, mientras manejaba. En el cenit de la crisis siente que se aferra al volante y sus piernas se ponen rígidas con los pies firmes sobre los pedales sin poder soltarlos. Luego pierde el conocimiento y se entera por el relato de su madre que logra girar a un costado de la ruta, mientras que la madre con gran esfuerzo logra desprenderla del volante y los pedales, apagando el motor con la llave de encendido.

En su relato menciona que tanto en los momentos previos como en el transcurso de la crisis se le presenta la imagen de una estampita que lleva en el auto del "Jesús de la Misericordia" y la leyenda que este porta -enigmática al principio- "Jesús de la Misericordia, solo en ti yo confío". Revisando su vida reciente reconoce que esta imagen se le ha ido presentando con frecuencia, por ejemplo la encuentra en su Agenda, en un libro que recibe "casualmente", un señalador de página, etc.; por lo que se interroga si será un mensaje que tiene que recibir. A partir de lo cual afirma que Jesucristo es el único hombre en el que ella confía.

Comentario:

"Jesucristo de la Misericordia" es la figura que materializa la búsqueda de compadecimiento y remedio de los pecados y miserias. Esta figura le permite sostener por delegación responsabilidades y decisiones que ella no puede supuestamente afrontar; con la esperanza de recibir respuestas de la Providencia. Convoca entonces el don como hecho de estructura. De este modo $\mathrm{M}$ en su recorrido terapéutico pasa de la solicitud de auxilio -ante las convulsiones- al "dar" como cuestión.

Tanto el órgano del cerebro donde se referencia el feedback como norma de lo viviente y del lazo; como la posterior imagen de Jesucristo, se sitúan a nivel de la imagen del semejante que notamos con la notación algebraica lacaniana "i (a)" en que se sostiene el sujeto supliendo un sostén simbólico dado que el Otro está elidido. $\mathrm{M}$ ha sustituido el órgano del cerebro y su anterior orden espiritual-cibernético concomitante por la actual referencia del Jesucristo de la Misericordia y desde entonces, y no sabemos por cuánto tiempo, no ha vuelto a tener una crisis epiléptica.

Jesucristo de la Misericordia es una figura que produce y corresponde a la extracción de un rasgo que toma consistencia por la elevación que permite lo imaginario. Jesucristo es lo de que Dios toma cuerpo precisamente. Allí comienza lo que ella llama el camino de su sanación. 
4- De la sanación

$\mathrm{M}$ relata que ha participado en un retiro en un pueblo de la provincia de C. donde existe una congregación religiosa a cargo de un cura sanador, participa de los rituales y finalmente deja de tener dolores y pesares. M reafirma en estas ceremonias su fe en Jesucristo de la Misericordia y pasa a oficiar de Mediadora para la cura de otras personas. Retoma el dictado de los Seminarios pero ahora con temas religiosos y con la forma de una conversación.

\section{Comentario:}

Jesucristo, lo que de Dios toma cuerpo, es el único hombre en que confía. Ella no cree en ningún hombre particular, no cree allí, no se engaña respecto de lo real del sexo. Solo cuenta con un Hombre (con mayúsculas) que en posición de excepción se sustrae a la castración, sin contar con el conjunto de la estructura de la sexuación. Este Un-Hombre que no participa de la función fálica es el lugar de falla, punto exterior a partir del cual se funda la estructura y donde se articula la pulsión de muerte y por su incidencia más allá de la epilepsia, hace agitar el anudamiento de lo real, lo simbólico y lo imaginario.

A modo de conclusión y luego de la lectura de las notas clínicas, se advierte que el hilo del síntoma -o lo que hace las veces de síntoma- y su alojamiento clínico, posibilita la interlocución e intercambio de los abordajes diferenciales de la medicina y el psicoanálisis.

\section{Referencias}

Ansermet, F. \& Magistretti, P. (2006). A cada cual su cerebro. Plasticidad Neuronal e Inconsciente. Buenos Aires: Katz Editores.

Fouchet, P. (2003). Le phenoméne épileptique. Revue Internationale de Sante Mentale et Psychanalyse Appliquée, 12. Ed.Nouvelle École Lacanienne.

Freud, S. (1988). Proyecto de una psicología para neurólogos. Obras Completas Volumen I, p. 323-393. Buenos Aires: Amorrortu Editores.

Freud, S. (1988). Esquema del Psicoanálisis. Obras Completas Volumen XXIII. Buenos Aires: Amorrortu Editores.

Kandel, E. (2007). En busca de la memoria. Buenos Aires: Katz Editores.

Lacan, J. (1965). Escritos. México. Ed. FCE.

Lacan, J. (1986). Psicoanálisis y Medicina. En: Lacan, J. Intervenciones y Textos $n^{\circ}$ 1, p. 86-89. Buenos Aires: Editorial Manantial.

Lacan, J. (1987). El Seminario Libro XI. Los cuatro conceptos fundamentales del Psicoanálisis. Buenos Aires: Editorial Paidos.

Lacan, J. (1988). Conferencia en Ginebra sobre el síntoma. En: Lacan, J. (1988) Intervenciones y Textos $n^{\circ}$ 2, p. 115-144. Buenos Aires: Editorial Manantial.

Milner, J.C. (2000). Introducción a una Ciencia del Lenguaje. Buenos Aires:

Ediciones Manantial.

Raimbault, G. (1995) El Psicoanálisis en las fronteras de la Medicina. Buenos Aires, Argentina: Ariel. 
Soler, C. (2002). Descartes con Freud. En: Psicoanálisis y Medicina-Dolencias hacia el sintoma. Buenos Aires. Editorial. Atuel-Cap.

Springer, S \& Deutsch, G. (2001). Cerebro izquierdo-cerebro derecho. Barcelona: Editorial Ariel Neurociencia.

Recibido: 05 de noviembre de 2010

Aceptado: 12 de abril de 2012 